\title{
A Randomized, Double-Blind, Pilot Study of the Effect of Famotidine on Acotiamide Treatment for Functional Dyspepsia
}

\author{
Mariko Hojo ${ }^{a}$ Akihito Nagaharac Daisuke Asaoka ${ }^{a}$ Tsutomu Takeda ${ }^{a}$ \\ Kentaro Izumi $^{a}$ Kohei Matsumoto ${ }^{a}$ Hiroya Ueyama $^{a}$ Yuji Shimada $^{c}$ \\ Kenshi Matsumoto $^{a}$ Shuko Nojirib Sumio Watanabe ${ }^{a}$ \\ ${ }^{a}$ Department of Gastroenterology, Juntendo University School of Medicine, and ${ }^{b}$ Clinical Research Support Center, \\ Juntendo University, Tokyo, and ' Department of Gastroenterology, Juntendo University Shizuoka Hospital, \\ Shizuoka, Japan
}

\section{Keywords}

Functional dyspepsia $\cdot$ Acotiamide $\cdot$ Famotidine $\cdot$ Epigastric pain syndrome $\cdot$ Postprandial distress syndrome

\begin{abstract}
Background/Aims: Acotiamide, a prokinetic drug, is used to treat functional dyspepsia (FD), especially postprandial distress syndrome (PDS). However, a treatment for FD patients with PDS and/or epigastric pain syndrome (EPS) has not been established. We investigated the efficacy of famotidine in combination with acotiamide for FD. Methods: Fifty blindly randomized FD patients received placebo with acotiamide, or famotidine with acotiamide, for 4 weeks. Treatment efficacy was assessed by overall treatment effects (OTE), total, PDS and EPS symptom scores, and impairment of quality of life (QOL). Results: After OTE assessment, patients who felt affected by treatment comprised 40.9 and $57.9 \%$ of famotidine and placebo groups, respectively, after 4 weeks' treatment, with no significant difference between groups. A significant decrease was seen in total, PDS, and EPS symptom scores, and in QOL impairment, after 4 weeks' treatment compared with pretreatment scores for famotidine and placebo groups, but was not observed between groups. The proportion of patients showing a $\geq 50 \%$ decrease in EPS
\end{abstract}

\section{KARGER}

E-Mail karger@karger.com www.karger.com/dig
(C) 2017 The Author(s)

Published by S. Karger AG, Basel

Karger

Open access

This article is licensed under the Creative Commons AttributionNonCommercial-NoDerivatives 4.0 International License (CC BYNC-ND) (http://www.karger.com/Services/OpenAccessLicense) Usage and distribution for commercial purposes as well as any distribution of modified material requires written permission. symptom scores was greater in the famotidine than that in the placebo group for every observation point, with the greatest difference observed after 2 weeks' treatment. Conclusion: The effectiveness of famotidine and acotiamide combination therapy in FD was similar to the effectiveness of acotiamide therapy alone.

(C) 2017 The Author(s)

Published by S. Karger AG, Basel

\section{Introduction}

Currently, acid-suppressive or prokinetic drugs are recommended as first-line treatments for functional dyspepsia (FD) [1,2]. Moreover, according to the subgroups defined by the Rome III committee, proton pump inhibitors (PPIs), being the acid-suppressive drugs that they are, are recommended as initial therapy for epigastric pain syndrome (EPS), while prokinetics is recommended as initial therapy for treating postprandial distress syndrome (PDS) [3].

Acotiamide, a prokinetic drug has recently been developed in Japan for the treatment of FD [4]. The drug inhibits acetylcholinesterase activity and also enhances acetylcholine release via the antagonism of muscarinic M1 and M2 receptors [5]. Such receptors are thought to be 
Fig. 1. Study design. OTE, overall treatment effect; QOL, quality of life.

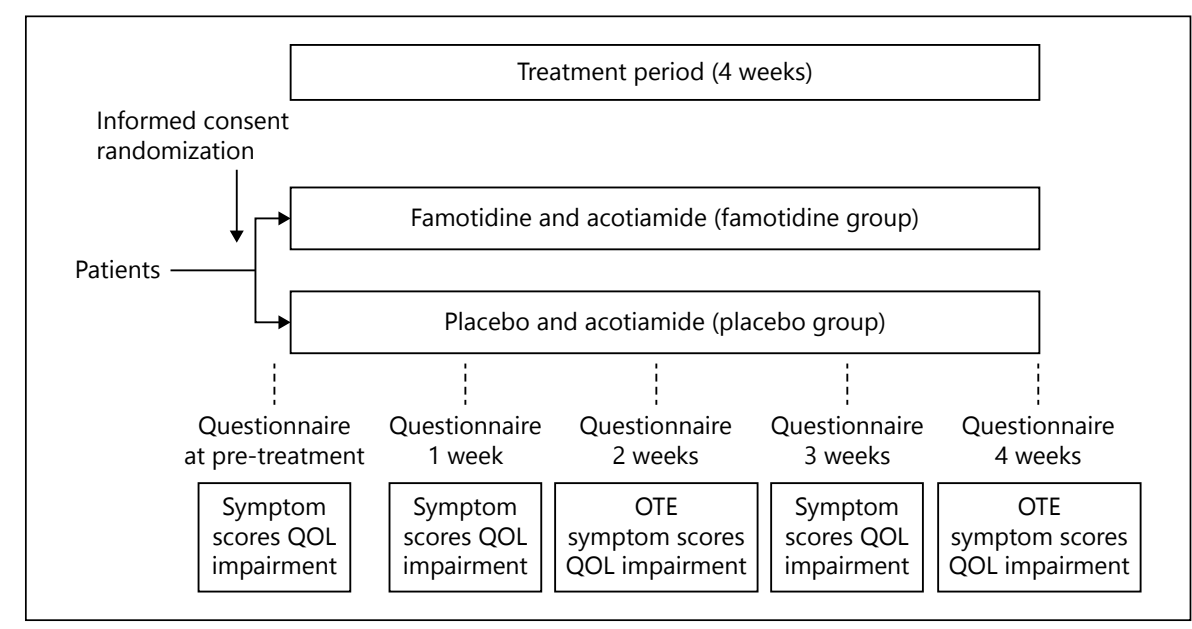

responsible for the formation of a negative-feedback loop within neuromuscular junctions [5]. As a result, the drug causes an increase in the concentration of acetylcholine at neuromuscular junctions, thereby resulting in enhancing the force of muscle contractions and gastric emptying. Although acotiamide shows efficacy in the management of FD, it is more effective in the treatment of PDS $[4,5]$.

Many FD patients show symptoms of both PDS and EPS; however, a treatment for such FD patients has not been established. An overlap of PDS and EPS symptoms suggests that combination therapy with acotiamide and acid-suppressive drugs may be more effective for FD; however, a randomized placebo-controlled study has never been undertaken.

We, therefore, conducted this study to investigate any possible additive effect of an acid-suppressive drug on acotiamide treatment of FD patients. However, acotiamide, but not PPIs, has been approved by the Japanese government's insurance system for FD. In Japan, chronic gastritis involves not only histological chronic active gastritis but also FD [6]. The treatment of chronic gastritis with histamine 2 receptor antagonists is covered by insurance, and was reported to be effective in relieving FD symptoms in a meta-analysis of the Cochrane Database [7], including a famotidine trial [8]. Accordingly, for this study, we chose famotidine ( $10 \mathrm{mg} 2$ times daily, the dose covered by insurance for chronic gastritis) as an anti-acid suppressive drug that is available clinically for the treatment of FD.

\section{Materials and Methods}

\section{Patients}

Studies were performed on FD patients who fulfilled the criteria mentioned in the pragmatic definition found in the ROME
III classification [1]. Study participants were recruited from patients who complained of chronic upper abdominal symptoms, such as postprandial fullness, epigastric pain, belching, and nausea, and who wanted treatment for these symptoms. They had undergone an upper gastrointestinal endoscopy within 6 months prior to recruitment. All patients were at least 20 years of age, and endoscopy showed that they did not have any physical abnormality that may have explained their abdominal symptoms. Patients whose chief complaints were heartburn and/or acid regurgitation, who had received eradication therapy for Helicobacter pylori within 1 year with its consequent disappearance, who had received acid-suppressive agents and/or acotiamide within 1 week, who had a past history of gastrointestinal resection, who had a history of intestinal diseases such as colonic cancer or inflammatory bowel disease, who had serious hepatic, renal, or cardiac disease, who were or might have been pregnant, or who were lactating were excluded from this study. The study protocol was reviewed and approved by the University Ethics Committee. This study was conducted in accordance with the principles of the Declaration of Helsinki and a written informed consent was obtained from every patient. This study was registered with the University Hospital Medical Information Network Clinical Trials Registry (UMIN000012082).

\section{Study Design}

This randomized, double-blind pilot trial was conducted at a single university hospital between November 2013 and April 2015. The study design is summarized in Figure 1. Eligible patients were randomly allocated to receive famotidine at a dose of $10 \mathrm{mg}$ or a placebo, made up of $10 \mathrm{mg}$ doses of lactose hydrate, after meals twice a day, together with acotiamide at a dose of $100 \mathrm{mg}$ before meals, 3 times a day for 4 weeks.

\section{Randomization}

The Department of Pharmacy at the university hospital, as an arms-length, third-party organization, randomly assigned patients by the envelope method to either a famotidine or a placebo treatment arm. Investigators and patients were blinded to patient allocations.
Hojo et al. 


\section{Efficacy Assessments}

The efficacy of treatment was assessed on the basis of an overall treatment effect (OTE) approach [9]. At the time or at the completion of treatment, patients were given a self-assessment questionnaire with questions such as: "How were your symptoms during the past week compared with the pretreatment phase?" Patients were asked to score the severity of symptoms on a 7-point Likert scale (1, extremely improved; 2 , improved; 3 , slightly improved; 4 , unchanged; 5 , slightly aggravated; 6 , aggravated; 7 extremely aggravated). Patients who were "extremely improved" or "improved" were considered responders based on an OTE.

To assess the effects of treatment on symptoms, patients were asked to score the severity ( 0 , absent; 1 , mild; 2 , moderate; 3 , severe) of 9 epigastric symptoms (upper abdominal pain, upper abdominal discomfort, postprandial fullness, upper abdominal bloating, early satiety, nausea, vomiting, excessive belching, and heartburn). This same questionnaire had already been adopted in previous trials of acotiamide $[5,10]$. An additional explanation of upper abdominal discomfort, meaning discomfort except postprandial fullness or upper abdominal bloating, was provided to patients. A total abdominal symptom score was calculated by adding each score for the 9 epigastric symptoms. An EPS symptom score was calculated by adding each score for upper abdominal pain and upper abdominal discomfort. A PDS symptom score was calculated by adding each score for postprandial fullness, upper abdominal bloating, and early satiety. Responders were identified by symptom scores that indicated a clinically meaningful improvement of symptoms, and were defined as patients for whom symptom scores decreased by $\geq 50 \%$ compared with their pretreatment scores [5].

The effects of treatment on the disease-specific quality of life (QOL) of each patient were assessed using an Izumo scale questionnaire based on symptoms frequently noted by Japanese patients, with the inclusion of upper and/or lower abdominal symptoms [6, 11]. The use of this questionnaire is recommended for the assessment of symptoms according to Japanese FD guidelines [2]. This scale included 15 questions divided into 5 categories: reflux, pain, fullness, constipation, and diarrhea. Questions were rated on a 6-point Likert scale ( 0 , not bothered; 1 , not so bothered; 2 , slightly bothered; 3, bothered; 4, strongly bothered; 5 , intolerably bothered). Epigastralgia-related and/or epigastric fullness-related QOL impairments were evaluated by the sum of scores obtained for the type of pain and/or fullness, respectively. Questions on the type of pain felt by patients were as follows: "Are you bothered by epigastric pain?"; "Are you bothered by hunger epigastric pain?"; and "Are you bothered by an epigastric burning sensation?” Questions on the type of fullness were as follows: "Are you bothered by early satiation?"; "Are you bothered by postprandial long-lasting epigastric fullness or nausea?"; and "Are you bothered by epigastric bloating?" [11].

\section{Primary Efficacy Endpoints}

The 2 primary efficacy endpoints were the rate of responders based on an OTE every 2 weeks; and weekly total abdominal, EPS, and PDS symptom scores from the pretreatment phase to the completion of the study.

\section{Secondary Efficacy Endpoints}

Secondary endpoints were as follows: the percentage of patients for whom symptom scores decreased by $\geq 50 \%$ compared with pretreatment scores at each observation time; and weekly epigastralgia-related or epigastric fullness-related QOL impairments, from the time of pretreatment till the time of study completion.

\section{Statistical Analysis}

Efficacy analysis was based on the full analysis set (FAS), with at least one assessment of efficacy after the initiation of study treatment [12]. All analyses were undertaken using SAS software version 9.4 (SAS Institute, Cary, NC, USA). Differences in baseline characteristics between the famotidine group, in which patients received famotidine with acotiamide, and the placebo group, in which patients received placebo with acotiamide, were analyzed using a chi-square test, and Student $t$ test. To assess efficacy, the rate of responders based on an OTE was compared at each observation point within and between famotidine and placebo groups by Fisher's exact test. Symptom scores and QOL impairments were compared between pretreatment and post- 4 week treatment scores within each treatment group using Student $t$ test. Any changes from baseline in symptom scores and QOL impairments were compared between famotidine and placebo groups. A repeated measures analysis (mixed models analysis) was performed in which a comparison of treatment groups at each observation point was performed. The level of significance was set at 0.05 .

\section{Results}

\section{Baseline Characteristics of Patients}

Fifty patients, who fulfilled inclusion and exclusion criteria for recruitment, were randomized to a famotidine or placebo group in equal numbers. Two patients from the famotidine group and 1 patient from the placebo group withdrew from the study, and thus, 47 patients were available for FAS analysis. For the 2 patients who withdrew from the famotidine group, data were not available after the initiation of study treatment (Fig. 2). The patient who withdrew from the placebo group did not receive the study drug at all. The baseline characteristics of patients for FAS analysis indicate that these were similar for both treatment groups, except for body weight (Table 1).

\section{Primary Efficacy Endpoints}

The responder rate, based on an OTE 2 weeks after the start of treatment, was $31.8 \%$ for the famotidine group and $21.1 \%$ for the placebo group. The responder rate 4 weeks after the start of treatment, namely, the time of completion of the study, was $40.9 \%$ for the famotidine group and $57.9 \%$ for the placebo group. For the famotidine group, a significant difference between the 2 observation points was not observed, while for the placebo group, the responder rate 4 weeks after the start of treatment increased significantly compared with the rate 2 weeks after the start of treatment $(p=0.03)$. At both 
Fig. 2. Summary of patient flow. ${ }^{\dagger}$ Diar-

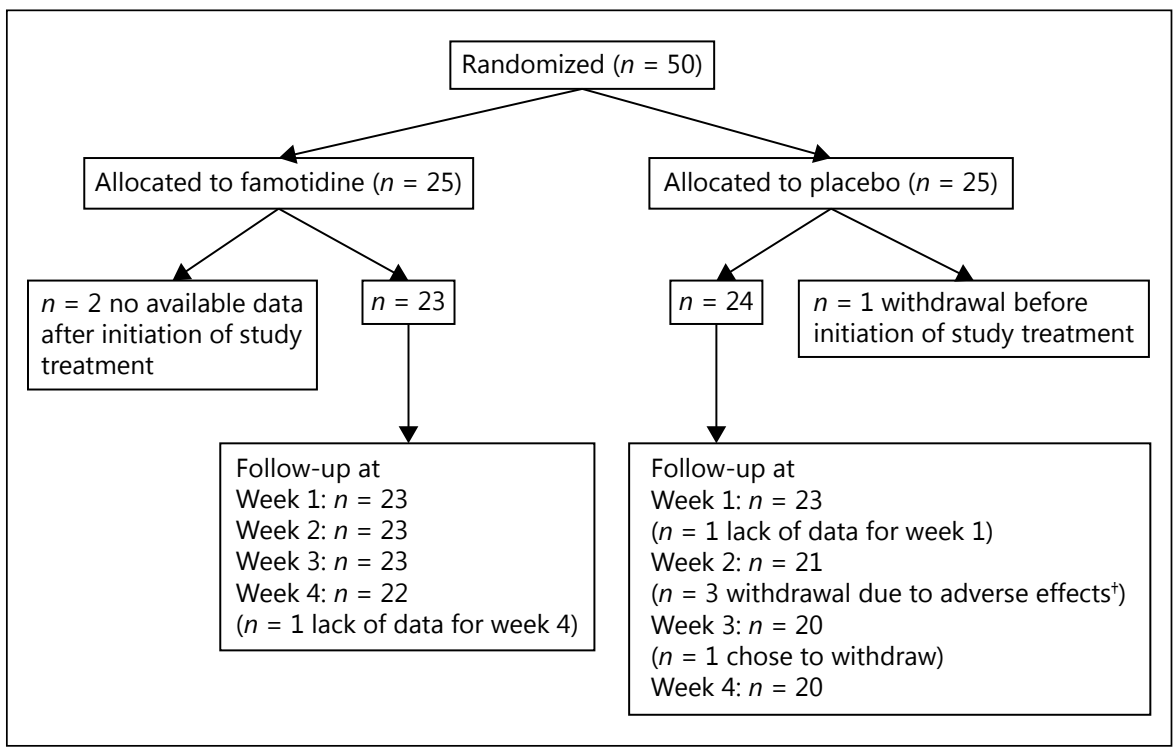
rhea, $n=2$; feeling of warmth, $n=1$.

Table 1. Baseline characteristics of the subjects in the full analysis set

\begin{tabular}{|c|c|c|c|}
\hline & $\begin{array}{l}\text { Famotidine } \\
\text { group, } n=23\end{array}$ & $\begin{array}{l}\text { Placebo } \\
\text { group, } n=24\end{array}$ & $p$ value \\
\hline Gender male:female, $n$ & $4: 19$ & $4: 20$ & ns \\
\hline Age, years, mean \pm SD & $45.0 \pm 15.0$ & $47.8 \pm 13.8$ & ns \\
\hline Body mass index, $\mathrm{kg} / \mathrm{m}^{2}$, mean $\pm \mathrm{SD}$ & $22.7 \pm 4.7$ & $19.1 \pm 2.3$ & 0.007 \\
\hline Helicobacter pylori, $n$ & & & ns \\
\hline Negative & 21 & 16 & \\
\hline Negative after eradication & 2 & 4 & \\
\hline Positive & 0 & 4 & \\
\hline Chief bothersome symptoms, $n$ & & & ns \\
\hline EPS-related symptoms & 9 & 8 & \\
\hline PDS-related symptoms & 7 & 13 & \\
\hline EPS- and PDS-related symptoms & 7 & 3 & \\
\hline Disease period, $n$ & & & ns \\
\hline Unknown & 2 & 3 & \\
\hline$<1$ month & 0 & 0 & \\
\hline $1 \leq,<3$ months & 3 & 4 & \\
\hline $3 \leq,<6$ months & 1 & 1 & \\
\hline $6 \leq,<12$ months & 2 & 4 & \\
\hline$\leq 12$ months & 15 & 12 & \\
\hline Total abdominal symptom scores, mean \pm SD & $9.7 \pm 4.25$ & $8.4 \pm 4.33$ & ns \\
\hline
\end{tabular}

observation points, significant differences between the 2 treatment groups were not noted (Fig. 3).

Total abdominal, EPS, and PDS symptom scores were significantly decreased after 4 weeks' treatment in comparison to scores before treatment for each treatment group ( $p<0.01$; Table 2). Significant differences between treatment groups in favor of adding famotidine were not observed when comparing changes from baseline for to- tal abdominal, EPS, and PDS symptom scores (mixedmodel analysis; $p=0.47, p=0.52, p=0.57$, respectively; Fig. 4).

\section{Secondary Efficacy Endpoints}

With regard to the proportion of patients whose EPS symptom scores decreased by $\geq 50 \%$ compared with pretreatment scores at each observation point, the pro- 
Fig. 3. Responder rates based on an overall treatment effect after 2 and 4 weeks of treatment. The responder rate refers to the percentage of patients who were "extremely improved" or "improved" by study treatment. ${ }^{*} p=0.03$ vs. placebo group, week 2 .

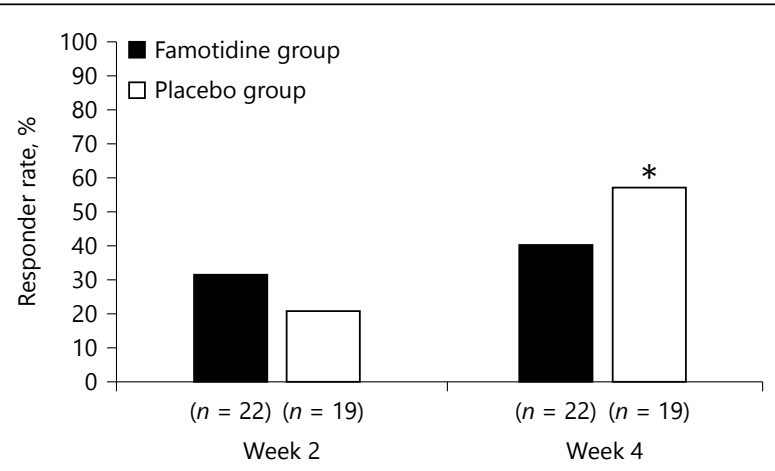

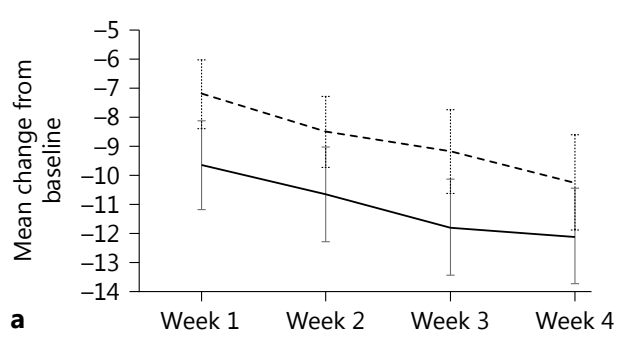
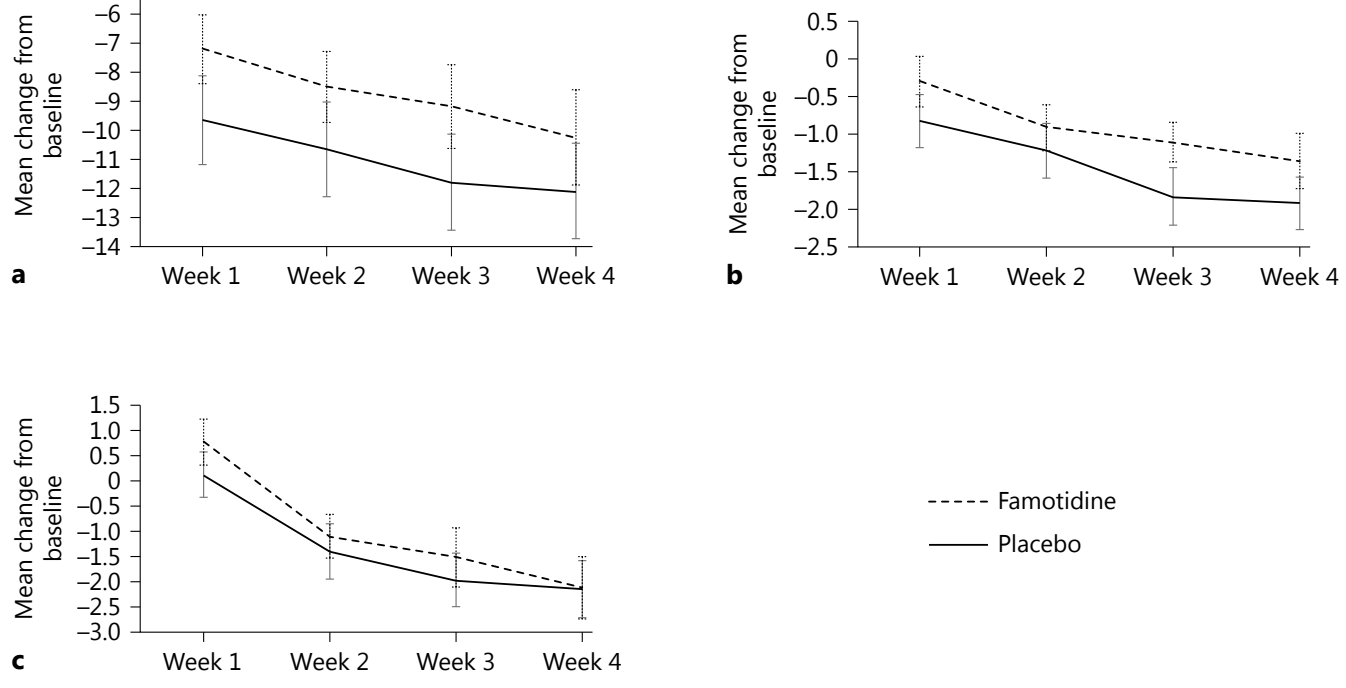

Fig. 4. a Mean \pm SE of the mean changes from baseline for total abdominal symptom scores. $\mathbf{b}$ Mean \pm SE of the mean changes from baseline for epigastric pain syndrome (EPS) symptom scores. c Mean \pm SE of the mean changes from baseline for postprandial distress syndrome (PDS) symptom scores.

Table 2. Weekly symptom scores from the pre-treatment phase till the completion of the study

\begin{tabular}{|c|c|c|c|c|c|c|}
\hline & $\begin{array}{l}\text { Baseline, } \\
\text { mean } \pm \text { SEM }(n)\end{array}$ & $\begin{array}{l}\text { At week } 1 \\
\text { mean } \pm \text { SEM }(n)\end{array}$ & $\begin{array}{l}\text { At week } 2 \\
\text { mean } \pm \text { SEM }(n)\end{array}$ & $\begin{array}{l}\text { At week } 3 \text {, } \\
\text { mean } \pm \text { SEM }(n)\end{array}$ & $\begin{array}{l}\text { At week } 4 \text {, } \\
\text { mean } \pm \text { SEM }(n)\end{array}$ & $p$ value* \\
\hline \multicolumn{7}{|c|}{ Total abdominal symptom score } \\
\hline Placebo group & $14.46 \pm 1.47(24)$ & $7.35 \pm 0.99(23)$ & $5.29 \pm 0.72(21)$ & $4.55 \pm 0.69(20)$ & $3.50 \pm 0.72(20)$ & $<0.0001$ \\
\hline \multicolumn{7}{|l|}{ EPS symptom score } \\
\hline Famotidine group & $2.87 \pm 0.34(23)$ & $2.04 \pm 0.31(23)$ & $1.65 \pm 0.34(23)$ & $1.04 \pm 0.26(23)$ & $1.09 \pm 0.23(22)$ & $<0.0001$ \\
\hline Famotidine group & $3.91 \pm 0.53(23)$ & $3.00 \pm 0.40(23)$ & $2.52 \pm 0.34(23)$ & $1.96 \pm 0.35(23)$ & $1.59 \pm 0.29(22)$ & 0.0009 \\
\hline Placebo group & $3.96 \pm 0.51(24)$ & $3.43 \pm 0.35(23)$ & $2.71 \pm 0.36(21)$ & $2.30 \pm 0.33(20)$ & $1.70 \pm 0.38(20)$ & 0.002 \\
\hline
\end{tabular}

* $p$ value, difference between pre- and post- 4 week treatment scores. EPS, epigastric pain syndrome; PDS, postprandial distress syndrome.

Famotidine and Acotiamide Treatment for FD 


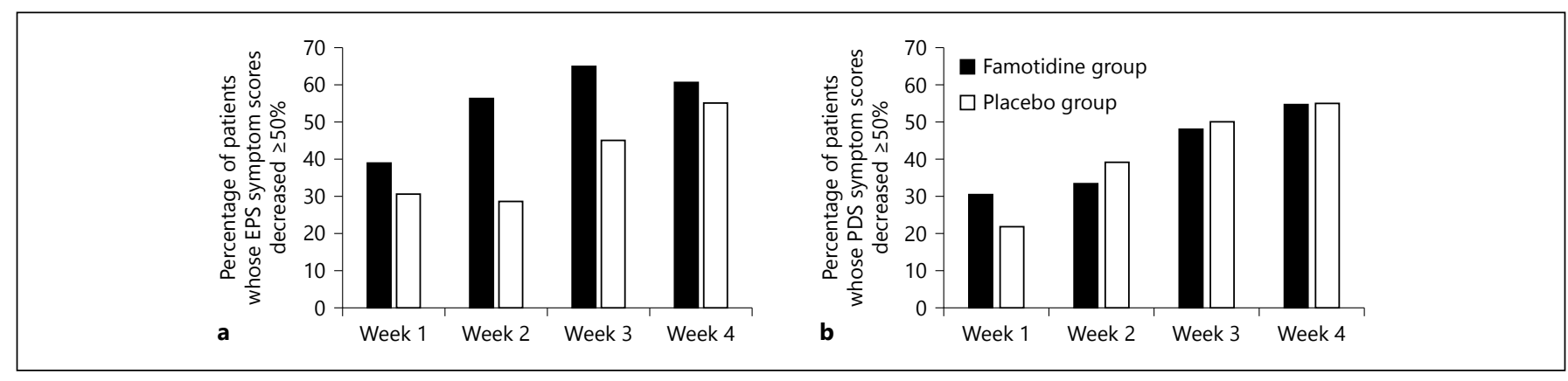

Fig. 5. a, b The percentage of patients whose symptom scores decreased $\geq 50 \%$ compared with pretreatment scores at each observation point. Epigastric pain syndrome (EPS) symptom scores. The proportion of patients in the famotidine group with EPS symptoms was higher than that for the placebo group at all observation points. Postprandial distress syndrome (PDS) symptom scores.

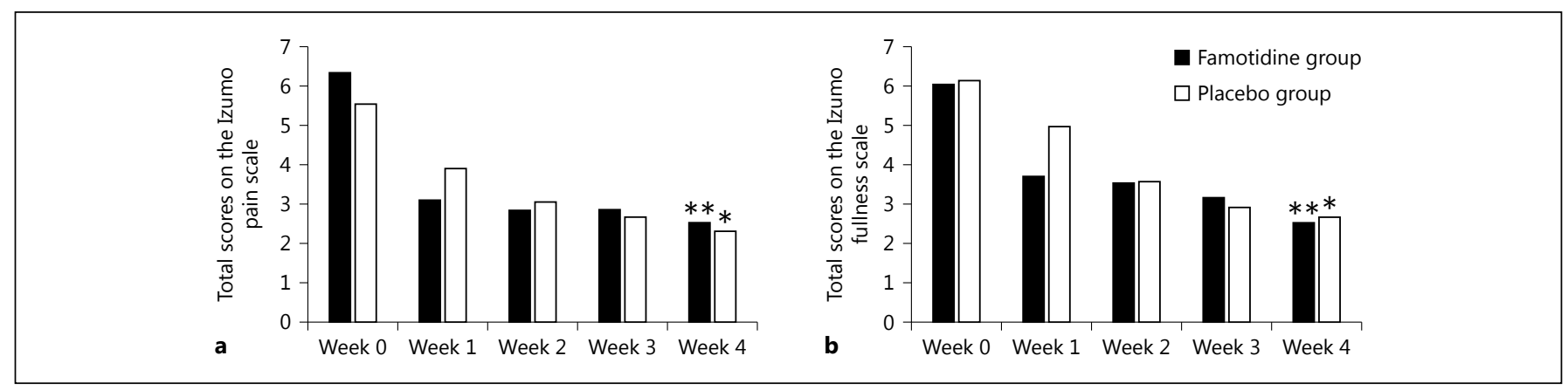

Fig. 6. Scores on the Izumo scale at weekly observation points. a Total scores for pain on the Izumo scale. Statistically significant decreases were observed by study treatment for both famotidine and placebo groups. b Total scores for fullness on the

portion showing decreased scores in the famotidine group was greater than that for the placebo group at all observation points (Fig. 5). The difference in percentages ranged between 5.9 and $28 \%$, with the greatest difference noted after 2 weeks' treatment. On the other hand, the proportion of patients with decreased PDS symptoms in the famotidine group was greater than that for the placebo group 1 week after the initiation of treatment, but less than that for the placebo group at the 2, 3, and 4 weeks' observation points.

Total scores obtained for both pain and fullness on the Izumo scale were significantly decreased for each group after a 4-week treatment in comparison with before treatment (Fig. 6). Statistically significant differences in efficacy were not observed between famotidine and placebo groups at each observation point (mixedmodel analysis; pain score: $p=0.52$; fullness score: $p=$ $0.27)$.
Izumo scale. Statistically significant decreases were observed by study treatment for both famotidine and placebo groups. ${ }^{*} p<$ 0.01 vs. week 0 , pretreatment. ${ }^{* *} p<0.001$ vs. week 0 , pretreatment.

Although adverse effects were found in 2 patients of the famotidine group - one had sleepiness and the other had constipation - they still completed the study protocol. Diarrhea as an adverse effect was apparent in 2 patients, and a feeling of warmth was present in 1 patient of the placebo group; these patients subsequently withdrew from the study.

\section{Discussion}

Although FD is not a life-threatening disease, it substantially lowers the QOL of affected patients and results in frequent medical consultations [13]. Current treatments for FD are inadequate, although acotiamide has recently been approved in the treatment of this disease $[4,10]$. For example, in phase II trials conducted in Europe and Japan, acotiamide has been efficient in FD patients with regard to meal-related symptoms such 
as upper abdominal bloating or postprandial fullness $[4,10]$.

Many FD patients show symptoms of both PDS and EPS. However, an effective treatment for such patients is not available. As acid-suppressive drugs, PPIs and prokinetics are recommended as initial therapy for EPS and PDS, respectively; such combination therapy is thought to be more effective for the treatment of FD than prokinetic monotherapy. However, to date, a randomized placebo-controlled study has not been undertaken. Only one study has investigated the efficacy of acotiamide in combination with esomeprazole for FD refractory to protonpump inhibitor monotherapy [14]. As a randomized controlled pilot study, our study is the first to examine the efficacy of combination therapy with a prokinetic and acid-suppressive drug for FD. Additionally, the treatment regimen consisting of acotiamide together with famotidine in the study can be prescribed for FD. As a result, this study is novel, one of its kind, and of appreciable clinical interest.

We found that total abdominal, EPS, and PDS symptom scores, which reflect the severity of symptoms of the primary endpoint, and pain-related and fullnessrelated QOL impairments of secondary endpoints, were significantly decreased in both famotidine and placebo groups. All symptom scores, including EPS symptom scores, were decreased by placebo treatment, which indicated that acotiamide was useful in the treatment of FD patients. It may thus be said that acotiamide was effective in the treatment of patients with EPS, as well as in those with PDS symptoms. Because placebo may have a relatively greater effect on FD than on organic diseases [2], the effectiveness of treatment of the placebo group with acotiamide may have been enhanced compared with the effectiveness of treatment of the single-arm trial.

Unfortunately, the addition of famotidine to acotiamide in the treatment of FD did not show any efficacy according to the primary efficacy endpoints of the current study. An OTE assessment did not show a significant difference between famotidine and placebo groups. The severity assessment of epigastric symptoms, based on total, EPS, and PDS symptom scores, also did not show a significant difference between both groups, although changes from baseline in all symptom scores for the famotidine group were greater than those of the placebo group at all observation time points. The QOL assessment of the secondary endpoint also did not show any significant difference between both groups.

Famotidine and Acotiamide Treatment for FD
Increase in patients whose EPS symptom scores decreased by $\geq 50 \%$ was observed in the famotidine group at all observation points when compared with the placebo group; in particular, the scores within the 2-week treatment period appeared to be noticeable. Therefore, the findings suggested that famotidine treatment might be effective for an early relief from symptoms in FD patients.

With regard to the limitations of this study, one major drawback was the low patient numbers studied in what was essentially a pilot study. The small sample sizes meant that a significant difference between patient groups could not be detected. Moreover, the 20-mg dose of famotidine used was relatively small, and is comparable to the $20 \mathrm{mg}$ per day used as a maintenance dose for duodenal ulcers [15]. Additionally, the continuous administration of histamine 2 receptor antagonists has been reported to induce a tolerance phenomenon: a 3-week continuous administration of lafutidine showed a significantly attenuated, acid-suppressing effect [16]. In our studies, the acid-suppressing effect of famotidine may have been attenuated 3 and 4 weeks after the initiation of treatment because of such a tolerance effect. As a result, any significant additive effect of famotidine may have disappeared, although famotidine may have contributed to early symptom improvement in FD patients. Such a tolerance phenomenon has not been reported for PPIs, and the degree and duration of acid suppression throughout $24 \mathrm{~h}$ of PPI treatment have been found to be greater than the degree and duration for $\mathrm{H} 2$ blockers [17]. Further clinical studies with greater sample sizes using acotiamide and PPIs or placebo are necessary to evaluate the efficacy of combination therapy of acotiamide and acid-suppressive agents for FD.

This study suggested that acotiamide was effective in improving EPS as well as PDS symptoms. Although combined famotidine and acotiamide therapy for FD did not show efficacy, famotidine was found to improve EPS symptoms at an early stage of treatment. Further clinical study, using another type of acid-suppressive agent in addition to acotiamide, is needed to clarify whether combination therapy with acotiamide and an acid-suppressive agent is more effective than acotiamide monotherapy in the treatment of FD.

\section{Disclosure Statement}

The authors declare no conflicts of interest. 


\section{References}

1 Tack J, Talley NJ, Camilleri M, Holtmann G, Hu P, Malagelada JR, et al: Functional gastroduodenal disorders. Gastroenterology 2006; 130:1466-1479.

2 Miwa H, Kusano M, Arisawa T, Oshima T, Kato M, Joh T, et al: Evidence-based clinical practice guidelines for functional dyspepsia. J Gastroenterol 2015;50:125-139.

3 Vanheel H, Tack J: Therapeutic options for functional dyspepsia. Dig Dis 2014;32:230234.

4 Matsueda K, Hongo M, Tack J, Aoki H, Saito Y, Kato H: Clinical trial: dose-dependent therapeutic efficacy of acotiamide hydrochloride (Z-338) in patients with functional dyspepsia - $100 \mathrm{mg}$ t.i.d. is an optimal dosage. Neurogastroenterol Motil 2010;22:618e173.

5 Matsueda K, Hongo M, Tack J, Saito Y, Kato $\mathrm{H}$ : A placebo-controlled trial of acotiamide for meal-related symptoms of functional dyspepsia. Gut 2012;61:821-828.

6 Kinoshita Y, Chiba T; FUTURE Study Group: Characteristics of Japanese patients with chronic gastritis and comparison with functional dyspepsia defined by ROME III criteria: based on the large-scale survey, FUTURE study. Intern Med 2011;50:2269-2276.
7 Moayyedi P, Soo S, Deeks J, Delaney B, Innes $M$, Forman D: Pharmacological interventions for non-ulcer dyspepsia. Cochrane Database Syst Rev 2006;4:CD001960.

8 Kato M, Watanabe M, Konishi S, Kudo M, Konno J, Meguro T, et al: Randomized, double-blind, placebo-controlled crossover trial of famotidine in patients with functional dyspepsia. Aliment Pharmacol Ther 2005; 21(suppl 2):27-31.

9 Ang D, Talley NJ, Simren M, Janssen P, Boeckxstaens G, Tack J: Review article: endpoints used in functional dyspepsia drug therapy trials. Aliment Pharmacol Ther 2011;33: 634-649.

10 Tack J, Masclee A, Heading R, Berstad A, Piessevaux H, Popiela T, et al: A dose-ranging, placebo-controlled, pilot trial of Acotiamide in patients with functional dyspepsia. Neurogastroenterol Motil 2009;21:272-280.

11 Kakuta E, Yamashita N, Katsube T, Kushiyama Y, Suetsugu H, Furuta K, et al: Abdominal symptom-related QOL in individuals visiting an outpatient clinic and those attending an annual health check. Intern Med 2011;50: $1517-1522$.
12 ICH Harmonised Tripartite Guideline. Statistical principles for clinical trials. International Conference on Harmonisation E9 Expert Working Group. Stat Med 1999;18:1905-1942.

13 Brook RA, Kleinman NL, Choung RS, Melkonian AK, Smeeding JE, Talley NJ: Functional dyspepsia impacts absenteeism and direct and indirect costs. Clin Gastroenterol Hepatol 2010;8:498-503.

14 Mayanagi S, Kishino M, Kitagawa Y, Sunamura M: Efficacy of acotiamide in combination with esomeprazole for functional dyspepsia refractory to proton-pump inhibitor monotherapy. Tohoku J Exp Med 2014;234: 237-240.

15 Texter EC Jr, Navab F, Mantell G, Berman R: Maintenance therapy of duodenal ulcer with famotidine. A multicenter United States study. Am J Med 1986;81:25-32.

16 Takahashi M, Katayama Y: Reversal of the tolerance phenomenon by the intermittent administration of a histamine $\mathrm{H} 2$-receptor antagonist. J Gastroenterol Hepatol 2010;25: 1493-1497.

17 Hunt RH: The relationship between the control of $\mathrm{pH}$ and healing and symptom relief in gastro-oesophageal reflux disease. Aliment Pharmacol Ther 1995;9(suppl 1):3-7. 